\title{
Ceramic catalyst combustors of Pt-loaded-alumina on microdevices
}

\author{
Woosuck SHIN, ${ }^{\dagger}$ Maiko NISHIBORI, Masayoshi OHASHI, Noriya IZU, Toshio ITOH and \\ Ichiro MATSUBARA
}

National Institute of Advanced Industrial Science and Technology (AIST), Shimo-Shidami, Moriyama-ku, Nagoya 463-8560

Ceramic catalysts for the integration of the combustor patterns onto microdevices have been prepared. The catalyst powder of $40 \mathrm{wt} \%$ Pt-loaded on alumina was mixed with the organic vehicle of terpineol and ethyl cellulose, to make various paste compositions of different particle concentration and ethyl cellulous. The pastes with $5 \mathrm{wt} \%$ and 10 wt\% ethyl cellulous have enhanced the linear Newtonian regions of the viscosity down to the shear rate about $5 \mathrm{~s}^{-1}$ and $0.1 \mathrm{~s}^{-1}$, respectively. For the dispensing the paste of $5 \mathrm{wt} \%$ ethyl cellulous and $13.7 \mathrm{vol} \%$ particle, the shear rate within the nozzle of $0.1 \mathrm{~mm}$ was calculated from the dispensed volume and speed to be 357 1/s and the viscosity data and yield stress data have been analyzed to be reasonable $0.3 \mathrm{~Pa} \cdot \mathrm{s}$, and $100 \mathrm{~Pa}$, approximately. The performance of the catalyst combustors dispensed on the microdevices have been carried out by the hydrogen mixed air gas flow, changing the catalyst temperature from 10 to $120^{\circ} \mathrm{C}$.

(C2009 The Ceramic Society of Japan. All rights reserved.

Key-words : Catalyst combustor, Ceramic paste, Rheology, Sensors, Dispenser

[Received December 8, 2008; Accepted March 17, 2009]

\section{Introduction}

For the development of chemical microsystem, the integration of functional material, mostly ceramic oxides, into the Si technology is the most interesting issue to improve the transducer characteristics of a sensor or actuator. Recent use of microsystem technologies in hot-plate type micro gas sensors became fundamental for the use of pulse heating, transient analysis, self cleaning processes as well as topics in microelectronics such as low power consumption, integration, and reliability. ${ }^{1)}$ However, the functional materials cannot always be obtained by the standard CMOS technology, sputtering, CVD. In these cases, transducer materials are obtained separately and novel technologies for the integration of such the active layers on microsystems are required.

In the case of the micro gas sensors, at least a part of the scientific and technical community considers the advantages of some typical chemical routes such as traditional precipitation or sol-gel, ${ }^{2)}$ which lead to sensitive, controlled and mass produced powders, instead of those such as thin film process using vacuum system. ${ }^{3}$ Among these chemical routes, prepared powder of functional materials are preferred to keep its function as the best, although this increases processing time and costs related to deposition equipment and handling. Sensors or actuators have also been obtained from dispensing the pretreated ceramic catalyst or sensing materials on the silicon micromachined substrates, and so-called micro-printing technology used in this sensor application are described elsewhere. ${ }^{4), 5)}$ Furthermore, the deposition of functional films, either by classical screen-printing or more sophisticated drop deposition techniques, such as ink-jet system is performed after combining the functional material with organic solution.

It has been recently demonstrated that dispensing technique

Corresponding author: W. Shin; E-mail: w.shin@ aist.go.jp can be successfully employed for the preparation of ceramic catalyst combustor with nanoparticles for gas-sensing applications. ${ }^{6)}$ Briefly, the devices were fabricated on double side polished p-type silicon. $\mathrm{Si}_{3} \mathrm{~N}_{4}$ has been used as dielectric membrane. The area of the membrane is approximately $1 \mathrm{~mm} \times 2 \mathrm{~mm}$, whereas the heated catalyst area is about $0.65 \mathrm{~mm}$ in diameter. On this micromachined thin dielectric surface, a paste containing the ceramic catalyst powders of Pt-loaded alumina is dispensed by through a nozzle with air pressure driving system to the membrane. For this, improved micromanipulator, micro-injector and visualization system are required. As a result, the micro-drop of ceramic catalyst has been deposited on the silicon device like that in Fig. 1 are obtained.

To control the rheological parameters of the paste is most important for the fabrication of the catalyst pattern, whose dimension changes the performance of the device. The process

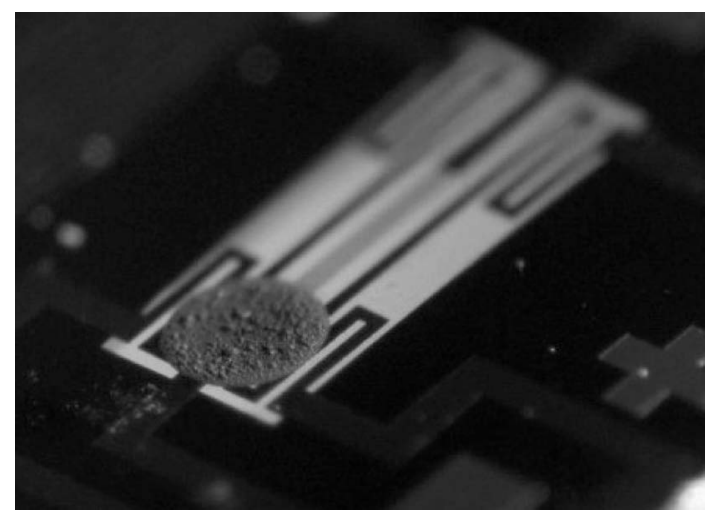

Fig. 1. Ceramic catalyst thick film pattern on the silicon micro-sensor device deposited as a paste droplet and dried thereafter. The circular catalyst is heated up by the micro-heater meander, Pt thin film pattern. 
parameters of paste dispensing are also strongly dependent on the rheological properties of the paste. Furthermore, the better understanding of the rheological properties of the paste will lead us to more advanced technology of 3-D forming such as reviewed. ${ }^{7), 8)}$

Speaking the rule of thumbs of the paste rheology, the viscosity of the catalyst pastes have been increased with the concentration of powder in the dispersant of terpineol or by adding ethyl-cellulous polymer. In this study, the viscoelastic properties of the paste have been investigated in quantitatively and discussed on the better control of dispensing fine ceramic patterns. We have changed the quantity of ceramic particle mixture, the adjustment method of dispersant with ceramics disperse by adding polymers. We have examined the viscoelasticity of the paste, and discussed how it affects the pattern formation characteristics.

\section{Experimental}

\subsection{Paste preparation}

Figure 2 shows the preparation of ceramic catalyst paste in this study. Pt-loaded on alumina (Pt/alumina) catalyst was prepared by impregnation of alumina with an aqueous solution of platinum (IV) chloride pentahydrate. A commercially available

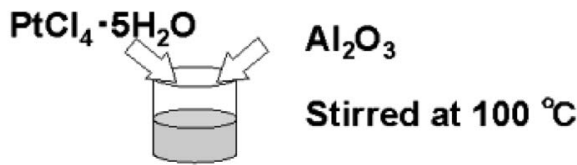

\section{Dry and Calcination}

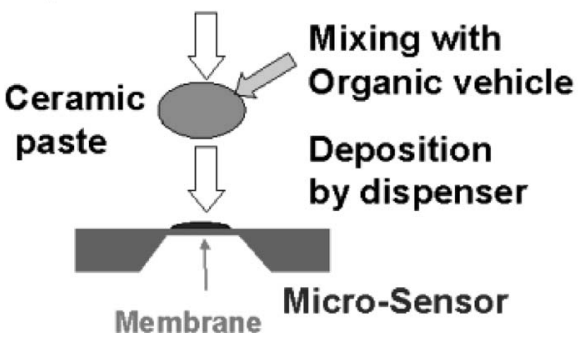

Fig. 2. Process of ceramic paste integration.
$\alpha-\mathrm{Al}_{2} \mathrm{O}_{3}$ (TM-10; TAIMEI Chemicals Co., Ltd., Tokyo, Japan) powder with an average particle size of $0.10 \mu \mathrm{m}$ was used. The slurry was stirred at $100^{\circ} \mathrm{C}$ for $30 \mathrm{~min}$, and then was dried at $120^{\circ} \mathrm{C}$ for $2 \mathrm{~h}$ in air. The concentration of Pt chloride pentahydrate in water was adjusted to the weight of alumina powder to make the final composition of $40 \mathrm{wt} \% \mathrm{Pt}$ in the catalyst. The details of the catalyst powder preparation were reported previously. ${ }^{9)}$

Before the catalyst powder was integrated on the microdevice, it was mixed with an organic vehicle to make ceramic pastes. The organic vehicle or dispersant was the terpineol and the dispersion of the particles can be controlled by preconditioning process such as ball milling powders or by adding polymer of ethyl cellulose, which is commercial and called Ethocel. The concentration of the particles changes the viscoelastic property of the system dramatically.

The mixing ratio in weight of the catalyst powder and the vehicle was also changed to control the viscosity of the paste. The content of ethyl-cellulous in terpineol in this study was changed to 0,5 , and $10 \mathrm{wt} \%$, as called T, TE05, and TE10, respectively. The amount of the catalyst powder and ethyl-cellulous in the paste is list up in Table $\mathbf{1}$.

The rheological characteristics of the paste were measured at $25^{\circ} \mathrm{C}$ on a rheometer (Thermo Haake RS300) by changing the shear rate, using the plate type sensor with the diameter $35 \mathrm{~mm}$ and the gap of $0.1 \mathrm{~mm}$. Viscosity also influences the thickness of the deposited paste droplet on the $\mathrm{SiO}_{2}$ top surface of Si substrate.

\subsection{Paste deposition}

The paste is dispensed by air pressure on the top of the syringe, but the viscosity and the shear rate inside the nozzle tip of the syringe decides the actual flow of the paste. The needle used for the experiment had an inner diameter of $0.1 \mathrm{~mm}$, nonwetting type tip (MUSASHI Engineering Inc., HN-0.1N). A desktop dispensing robot system with an image recognition function (MUSASHI Engineering Inc., FAD300s-ML 808FX) was used for paste dispensing. Typical condition for dispensing was a pressure of $40-50 \mathrm{kPa}$, and a dispensing time of $0.1-0.2 \mathrm{~s}$. The size of the deposited paste was controlled by changing these two parameters.

Table 1. Ceramic Pastes with Different Mixing Ratio (Weight or Volume) of Powder and Dispersant. (Density of Powder is $5.877 \mathrm{~g} / \mathrm{cc}$. Density of TE10 (10 wt\% Ethyl Cellulose) or TE05 (5 wt\% Ethyl Cellulose) is $0.935 \mathrm{~g} / \mathrm{cc}$, Same to that of Terpineol). The $\eta_{x}$ is the $\eta$ at Shear Rate of $x$

\begin{tabular}{|c|c|c|c|c|c|c|c|c|c|}
\hline symbol & dispersant & Powder wt $\%$ & Powder vol $\%$ & $\eta_{0.1}$ & $\eta_{1}$ & $\eta_{50}$ & $\eta_{200}$ & $\operatorname{Ln}\left(\eta_{1} / \eta_{0.1}\right)$ & $\operatorname{Ln}\left(\eta_{50} / \eta_{1}\right)$ \\
\hline \multirow[t]{4}{*}{$\mathrm{T}$} & Terpineol & $20 \%$ & $3.83 \%$ & & 0.16 & 0.14 & 0.0655 & & -0.1 \\
\hline & Terpineol & $33 \%$ & $7.37 \%$ & & 2.834 & 0.26 & 0.106 & & -2.4 \\
\hline & Terpineol & $50 \%$ & $13.73 \%$ & & 6.156 & 0.49 & 0.205 & & -2.5 \\
\hline & Terpineol & $67 \%$ & $24.14 \%$ & & 27.22 & 2.49 & 0.788 & & -2.4 \\
\hline \multirow[t]{4}{*}{ TE05 } & Terpineol $+5 \mathrm{wt} \%$ Ethocel & $20 \%$ & $3.83 \%$ & 2.8 & 0.41 & 0.28 & 0.273 & -1.9 & \\
\hline & Terpineol $+5 \mathrm{wt} \%$ Ethocel & $33 \%$ & $7.37 \%$ & 18.4 & 0.928 & 0.77 & 0.658 & -3.0 & \\
\hline & Terpineol $+5 \mathrm{wt} \%$ Ethocel & $50 \%$ & $13.73 \%$ & 95.4 & 3.408 & 2.89 & 2.234 & -3.3 & \\
\hline & Terpineol $+5 \mathrm{wt} \%$ Ethocel & $67 \%$ & $24.14 \%$ & 792 & 127.1 & 17.71 & 11.08 & -1.8 & \\
\hline \multirow[t]{4}{*}{ TE10 } & Terpineol $+10 \mathrm{wt} \%$ Ethocel & $9 \%$ & $1.57 \%$ & 11.3 & 2.204 & 2.19 & 1.962 & -1.6 & \\
\hline & Terpineol $+10 \mathrm{wt} \%$ Ethocel & $20 \%$ & $3.83 \%$ & 345 & 3.223 & 2.46 & 2.179 & -4.7 & \\
\hline & Terpineol $+10 \mathrm{wt} \%$ Ethocel & $33 \%$ & $7.37 \%$ & & 4.736 & 4.15 & 3.605 & & -0.1 \\
\hline & Terpineol $+10 \mathrm{wt} \%$ Ethocel & $50 \%$ & $13.73 \%$ & & 14.38 & 8.24 & 6.308 & & -0.6 \\
\hline
\end{tabular}


The paste drop was dried and then heated up to $300^{\circ} \mathrm{C}$ by $10 \mathrm{~h}$ and sintered for $2 \mathrm{~h}$ in air. During this process, the Pt particles were appeared and the color of the ceramic pattern became dark gray. The thickness and diameter of the sintered catalyst thick film was measured by an optical zoom microscope with 3-D measurement system (Hirox Inc., KH-3000 ST-HZ-CT-7).

For the deposited droplet characterization, a contact angle measurement system (Kyowa Interface Science Co., Ltd., DropMaster-500) was used. The dispensed droplet volume of the paste is calculated from the data of the contact angle between the paste drop and the substrate and the shape of the drop.

After deposition of the catalyst on the microdevice, the hydrogen combustion performance of the catalyst was investigated using gas-flow-type chamber which has been used in the previous works. With the gas flow $200 \mathrm{ccm}$ of $1 \mathrm{vol} \%$ hydrogen in air in the test chamber, the surface temperature of the catalyst and device have been monitored by IR camera and thermoelectric voltage signal from the device was also monitored. The catalyst was cooled down to $10^{\circ} \mathrm{C}$ by Peltier module, and the catalyst was heated up by the micro-heater (Fig. 1) on the device up to $120^{\circ} \mathrm{C}$.

\section{Results and discussions}

\subsection{Paste rheology}

Figure 3 shows the shear rate dependence of viscosity of ceramic paste with different particle concentrations. The flow behavior of terpineol and catalyst particle paste mixtures reflects the profound structural changes in the paste. Typically, as the viscosity decreased sharply with the shear rate, in the absence of polymers, the pastes exhibited so-called strong shear thinning behavior characteristic of a flocculated system. This can be expressed by Eq. (1).

$$
\eta=\frac{\tau_{o}}{\dot{\gamma}}+k \dot{\gamma}^{n-1}
$$

or in terms of shear stress,

$$
\tau=\tau_{o}+k \dot{\gamma}^{n}
$$

where, $\eta$ is viscosity, $\tau$ is stress, $\tau_{\mathrm{o}}$ is yield stress to initiate flow (in the case of solid-like paste), $\dot{\gamma}$ is shear rate and $k$ is consistency index. ${ }^{10)}$ For Newtonian liquid, the power term of parameter $n$ is 1 and $\tau_{\mathrm{o}}$ is 0 , but the paste with the particles became nonlinear and the power term of the shear rate became negative. The value of viscosity, $\eta$, of the three dispersant of terpineol (T), TE05, and TE10 are independent of shear rate, and 0.020, 0.050, and $0.45 \mathrm{~Pa} \cdot \mathrm{s}$, respectively, showing the Newtonian fluidic behavior (because their value are too small to plot in the Fig. 3, the $\eta$ of dispersant are omitted). However, even the paste of small particle contents and terpineol, $\mathrm{T}$ series, the viscosity became nonlinear as shown in Fig. 3. The parameter $n$ between the $\eta$ at shear rate 1 and 50 was evaluated and listed up in Table1.

The ethyl cellulous is commonly used polymer addictives for high viscosity and Newtonian flow, and this was added to enhance the fluidic mobility, in other words, the linearity. As expected, the linear behavior of $\eta$ higher shear rate was achieved in the case of TE05 and TE10 pastes, as shown in Figs. 3(b), (c). The pastes of TE05 show linear Newtonian regions down to the shear rate about $5 \mathrm{~s}^{-1}$, and those of TE10 show the linear region down to $0.1 \mathrm{~s}^{-1}$. Also the average viscosity increased as the TE05 and TE10 pastes exhibited the viscosity of $0.3-10$ and 2-10 Pa.s, respectively, in the linear Newtonian region.

Though the behavior of the paste with small amount of particles become rather linear by adding polymers but, with higher particle content, the mixtures reflocculate as evidenced by an
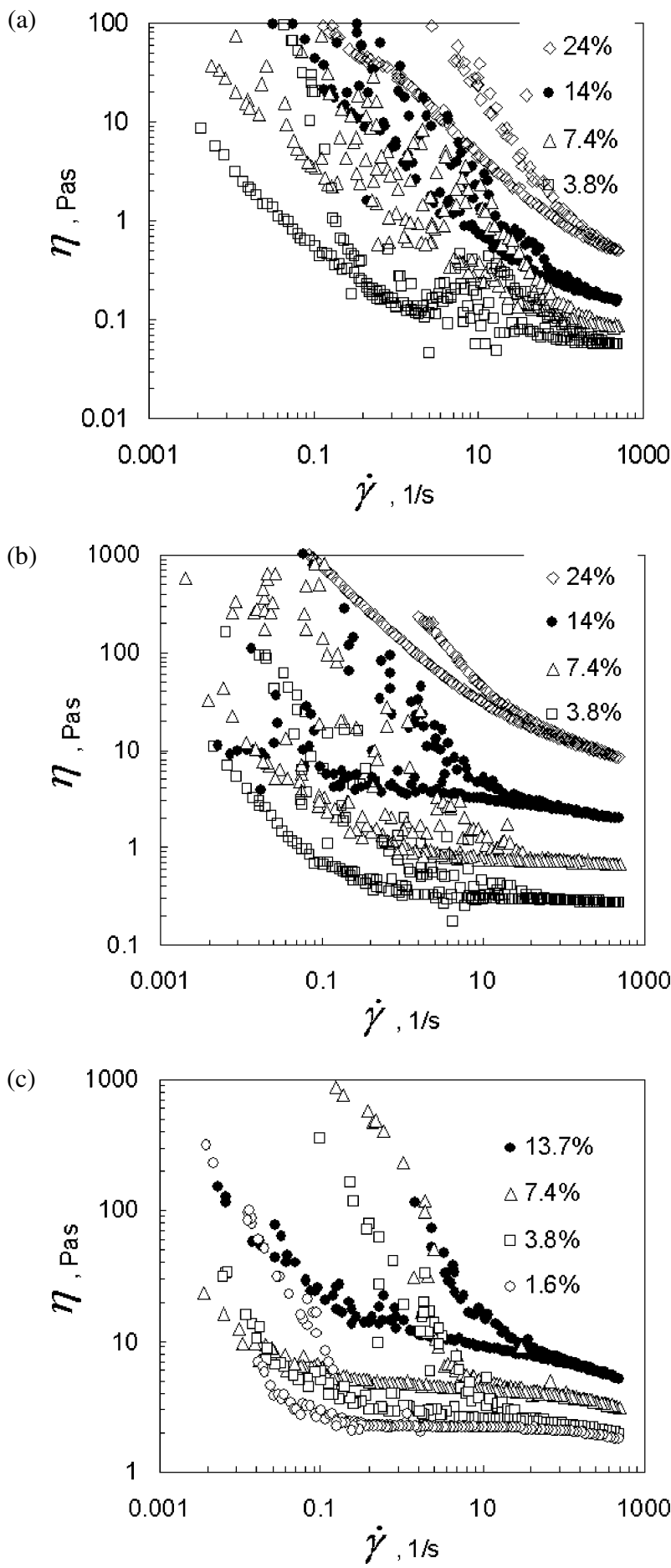

Fig. 3. Shear rate dependence of viscosity of the ceramic paste of different particle concentrations. The dispersant was (a) terpineol, mixtures of terpineol and (b) $5 \mathrm{wt} \%$, (c) $10 \mathrm{wt} \%$ ethyl-cellulous polymer (as called $\mathrm{T}, \mathrm{TE} 05$, TE10, respectively, in this report). In the case of TE10, the viscosity of the paste was too high to prepare any fluidic good paste with the particle volume content of $24 \%$. By this reason, a smaller content of $1.6 \%$ was additionally evaluated.

increase in the degree of shear thinning, as shown in the case of the TE05 paste, Fig. 3(b), with the particle content of $24 \%$. This degree of shear thinning decreased dramatically with increasing the polymer volume fraction in the pastes, as the flow behaviors of the paste mixtures with TE05 or TE10 and catalyst particle. 
These were also evaluated with the data of Fig. 3 and summarized in Table 1.

In our paste system, ethyl cellulose seems to play two roles; one is increasing the viscosity of the vehicle and the other is to disperse the ceramic particles, as shown in Fig. 4. With the help of this role of polymer, the dispersion by surface coating of the particles, the linear behavior of the paste at high shear rate region became possible. The coexistence of nonlinear and linear behavior in a single paste system is of key importance, which can control the dispensing process. This will be discussed later.

Figure 5 shows the dynamic viscosity behavior at $1 \mathrm{~Hz}$ of the ceramic paste with different particle concentrations. The real part of complex viscosity, $G^{\prime}$, decreased sharply over certain stress conditions. The fluid is considered to move easily over this shear stress. This value becomes large with the content of the particle, as shown in Figs. 5(a) and (b). Higher particle concentration requires larger stress to break down these coagulates. This is the typical curve for shear-thinning type paste. However, this is weakened in the cases of lower particle concentration of TE05 and all of TE10, with higher content of polymer. The abrupt decrease of $G$ ' was not shown in the case of TE10 for wide range of stress (or shear rate).

The paste mixed up with terpineol and 24 vol\% catalyst powder, shows very high $G^{\prime}$ around $5 \mathrm{kPa}$ at low stress region, which is linear up to the stress of $30 \mathrm{~Pa}$. As the shear thinning occurs and the $G^{\prime}$ decreased sharply down to below $1 \mathrm{~Pa}$. This critical stress point of the pastes decreased with their particle concentration, as clearly shown in Fig 5(a). This is explained in Fig. 6.

For the TE05, the situation seems to be similar, but the highest $G$ ' value is rather low. This also indicates that the addition of ethyl-cellulous changed the paste from solid-like to liquid-like. In other words, the fluidic movement strongly depends on the particle concentration if the polymer was not introduced. Furthermore, as the ethyl-cellulous content became large, the $G$ ' value of lower particle concentration increased relatively, and in the case of higher ethyl cellulous content, TE10, the $G$ ' of the paste less depends on the particle concentration.

In the linear region at high shear rate, the viscosity, $\eta$, increased with the particle content. The simplest description on this behavior is the Einstein equation (2a), but it is only good for very dilute system. And for the paste system in this study seems roughly follows the equation of Kreiger-Dougherty (2b), where the viscosity of the liquid dispersant is $\eta_{0}$, the content of the particle is $\Phi$, and the its maximum is $\Phi_{\mathrm{M}}$ (c.a. 0.64 for spherical particles).

$$
\begin{aligned}
& \eta / \eta_{\mathrm{o}}=1+2.5 \phi \\
& \eta / \eta_{\mathrm{o}}=\left(1-\frac{\phi}{\phi_{\mathrm{M}}}\right)^{K \phi_{\mathrm{M}}} \cong\left(1-\frac{\phi}{0.7}\right)^{K^{\prime}}
\end{aligned}
$$

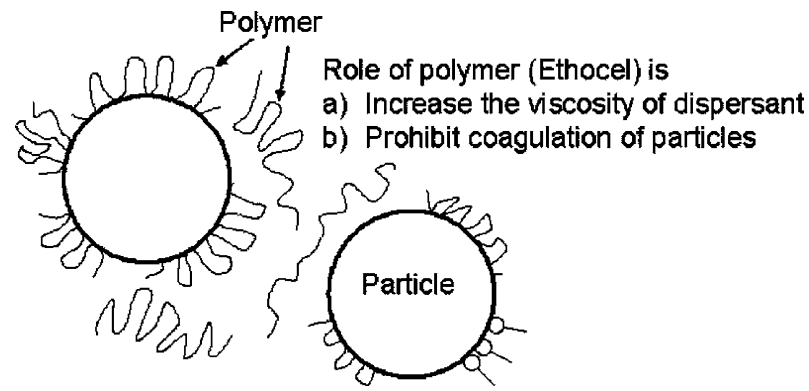

Fig. 4. Schematic model of the roles of polymer between the particles.
Figure 7 shows the plots of the paste viscosity at high shear rate with respect to the particle concentration for T, TE05 and TE10, and the expected plots using the Eqs. (2a) and (2b). We could guess that the paste of TE05 and TE10 have similar agglomeration, which changes the packing behavior of the particles in the flow. The parameters used for fitting the plot with the Eq. (2b) to the curves of the TE05 and TE10 would be useful for the future preparation and analysis of the paste.

(a)

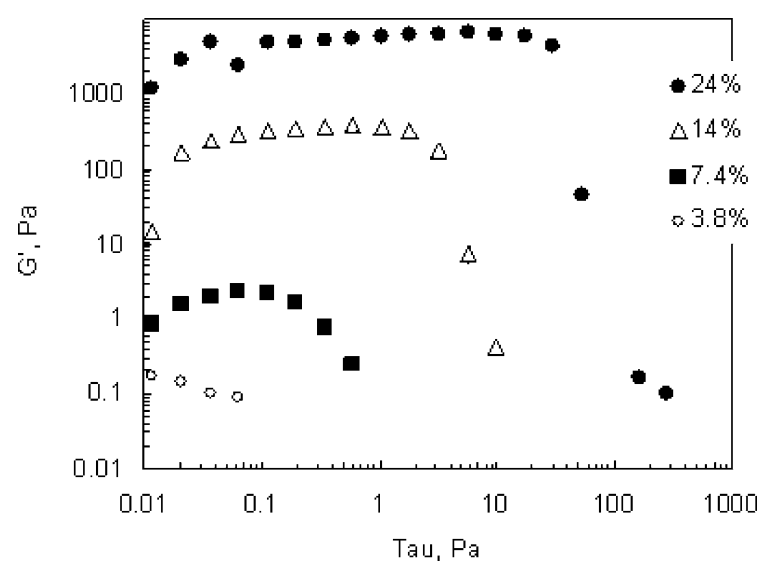

(b)

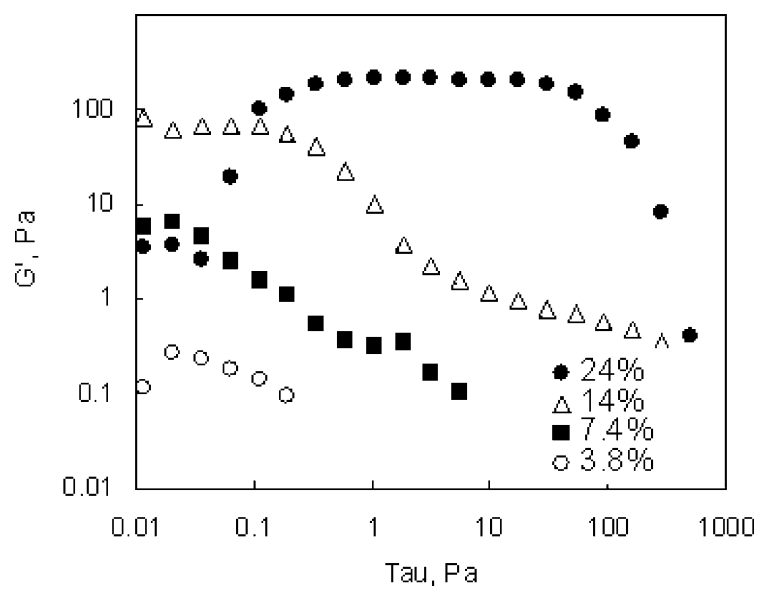

(c)

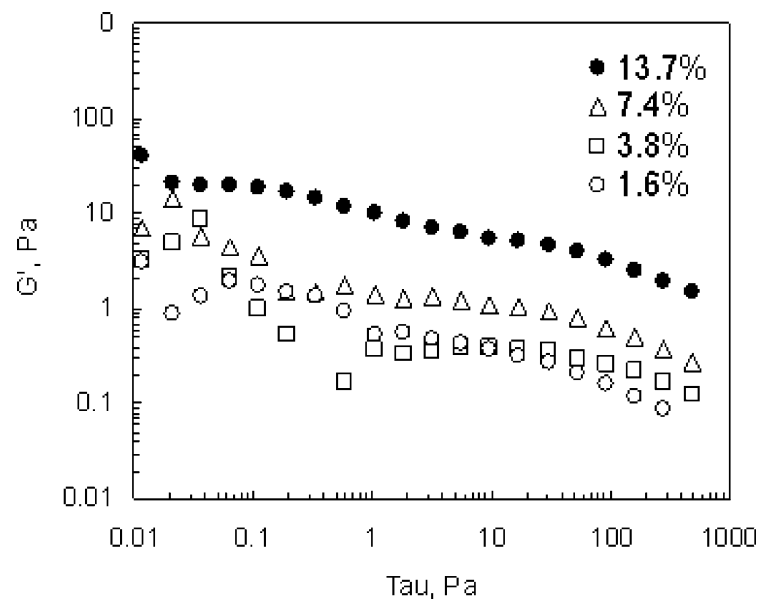

Fig. 5. Dynamic viscosity behavior at $1 \mathrm{~Hz}$ of the paste mixture of ceramic particles at different concentrations. The dispersant was (a) terpineol, mixtures of terpineol and (b) $5 \mathrm{wt} \%$, (c) $10 \mathrm{wt} \%$ ethyl-cellulous polymer (as called T, TE05, TE10). 


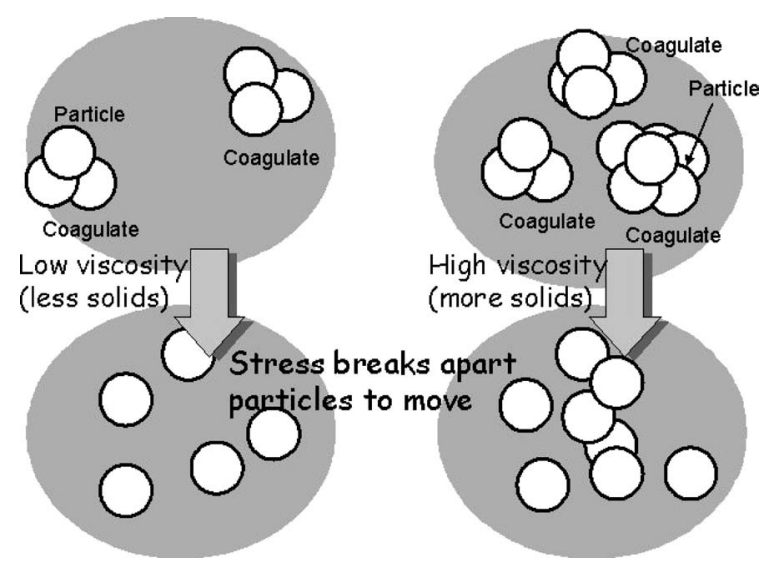

Fig. 6. Schematic model explaining that higher particle concentration requires larger stress to break down the coagulates.

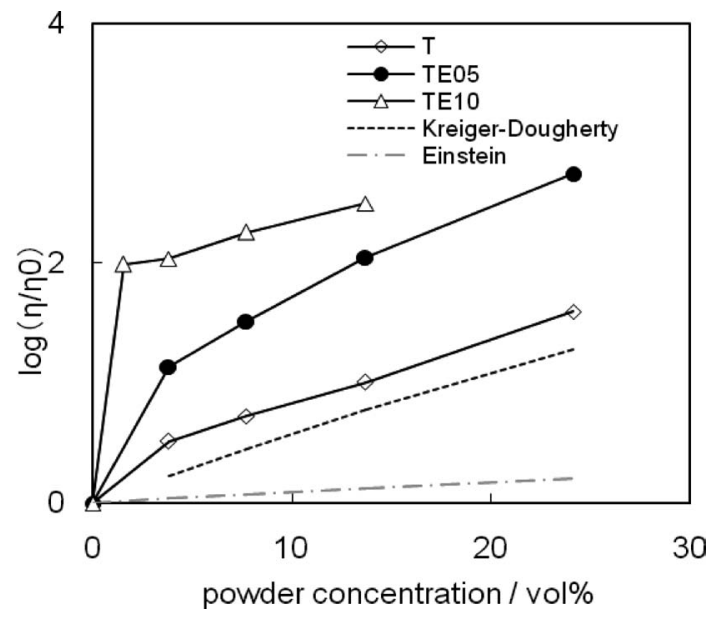

Fig. 7. Increase of viscosity at high shear rate at $200\left(\mathrm{~s}^{-1}\right)$ with particle concentration.

\subsection{Paste dispensing and deposition}

We have carried out the analysis of the yield stress of the paste during the dispensing process, and, first, the dispensed volume of the paste was evaluated. Table 2 shows the deposition control of dispenser with 3 different dispersants, T, TE05, and TE10. The contact angle of the drops on the substrate, $\mathrm{SiO}_{2}$ deposited $\mathrm{Si}$ wafer was determined from the silhouette of the drops, and the volume of the drop was also calculated. The details of the diameter and the height of the droplet are summarized in Table 2.

The main purpose of the observation of the silhouette of the drops is to determine the volume of every single droplet of different dispensing parameters. However, we could get secondary information of the wetting property of the paste on the substrate at the same time. Surface energy between the liquid and substrate is important because it affects both resolution and adhesion of the paste pattern on the substrate. A liquid that wets well will spread and thereby limit resolution. The interaction between a flat surface and a liquid drop is characterized by the contact angle. Figure 8 shows the droplet shape control of dispenser with 3 different dispersants. The contact angle increased linearly with the volume of the paste deposited, and it seems that the surface energy effect was not so much critical in our case. Furthermore, the contact angle increased with the content of particle and addition of ethyl-cellulous, i.e., viscosity.
Table 2. Dimensions of the Deposited Droplet of Various Paste Mixture System

\begin{tabular}{ccccc}
\hline particles in paste $(\mathrm{vol} \%)$ & 3.825 & 7.369 & 13.726 & 24.138 \\
\hline Terpineol & & & & \\
C.A. $\left({ }^{\circ}\right)$ & - & - & 20.9 & 33.4 \\
diameter $(\mu \mathrm{m})$ & - & - & 1043.2 & 303.8 \\
height $(\mu \mathrm{m})$ & - & - & 96.2 & 182.2 \\
volume $(\mu \mathrm{L})$ & - & - & 0.014 & 0.01
\end{tabular}

TE05

$\begin{array}{ccccc}\text { C.A. }\left({ }^{\circ}\right) & 4.1 & 11.6 & 27 & 43.6 \\ \text { diameter }(\mu \mathrm{m}) & 587.4 & 597.4 & 1012.6 & 860.8 \\ \text { height }(\mu \mathrm{m}) & - & 30.4 & 121.5 & 172.1 \\ \text { volume }(\mu \mathrm{L}) & - & 0.001 & 0.022 & 0.035\end{array}$

TE10

\begin{tabular}{ccccc} 
C.A. $\left({ }^{\circ}\right)$ & 13.2 & 16.5 & 25.3 & - \\
diameter $(\mu \mathrm{m})$ & 698.8 & 698.8 & 810.2 & - \\
height $(\mu \mathrm{m})$ & 40.5 & 50.6 & 91.6 & - \\
volume $(\mu \mathrm{L})$ & 0.002 & 0.003 & 0.01 & \\
\hline
\end{tabular}

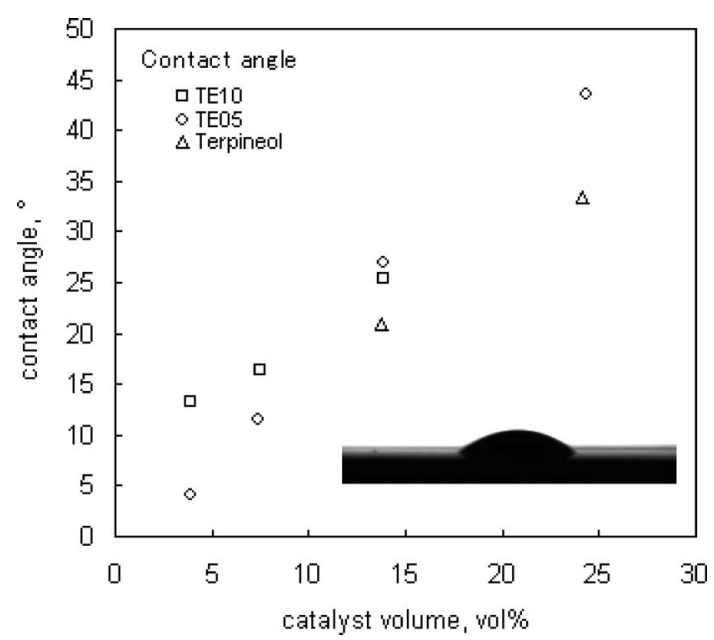

Fig. 8. Change of the contact angle with the dispensed catalyst paste volume on the substrate, $\mathrm{SiO}_{2} / \mathrm{Si}$ for the paste of 3 different dispersants. The angle was determined from the silhouette of the drops and the volume of the drop was also calculated.

\subsection{Flow behavior of paste}

The dispenser can be used to fabricate ceramic pattern using the paste with a wide range of rheological property, but the understanding of paste flow during the dispensing is essential for reliable and reproducible process. During dispensing, the paste experiences varying shear stresses and rates which affect the size and shape of the patterns. However, the dispenser operation can only control the parameters of air pressure inside the syringe and pressing time. Other parameters are decided by the needle used for dispensing. As shown above, the paste in this study is not Newtonian flow and to check the linearity of the dispensing condition is a kind of requisite steps for understanding the dispensing process. The paste series of TE05 with different particle concentration was tested as shown in Fig. 9. The needle used has 
(a)

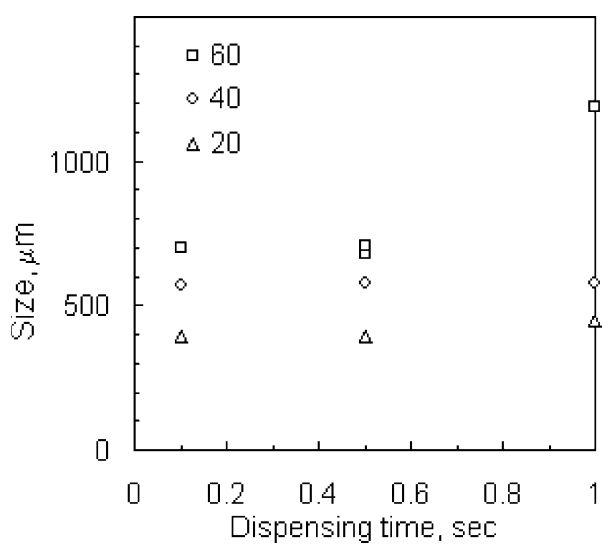

(c)

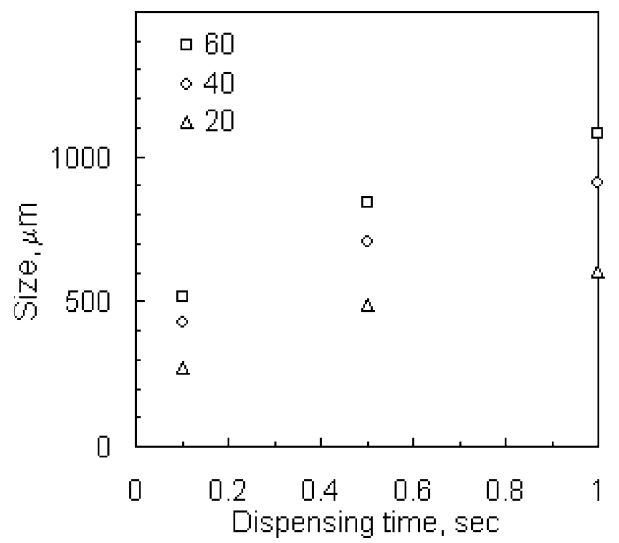

(b)

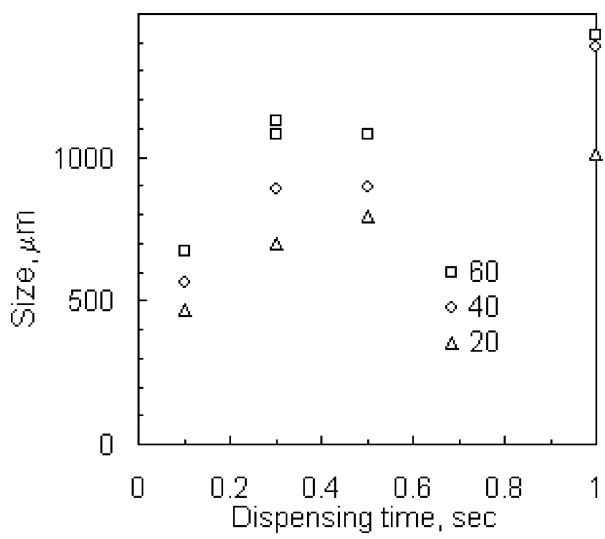

(d)

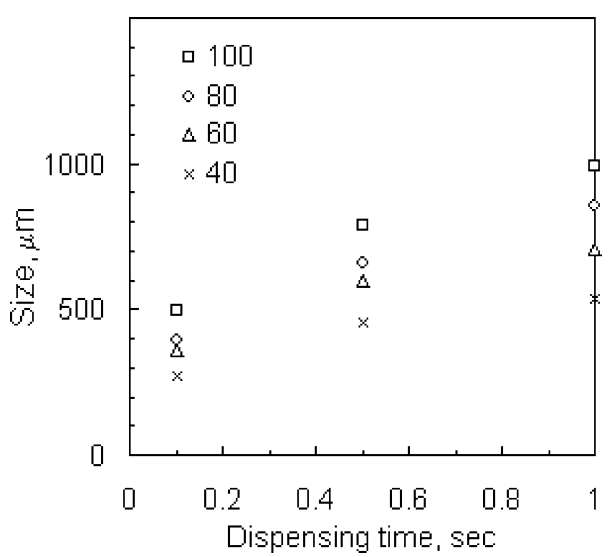

Fig. 9. Dispensing condition of the paste with different particle content. The dispersant is TE05. A nozzle of inner diameter $0.1 \mathrm{~mm}$ is used for (a) 3.8 , (b) 7.4, and (c) $13.7 \mathrm{vol} \%$, and nozzle of diameter $0.15 \mathrm{~mm}$ is used for (d) $24.1 \mathrm{vol} \%$. The values inside the plots are the dispensing air pressure $(\mathrm{kPa})$, and $20 \mathrm{kPa}$ was the lowest controllable air pressure of the dispenser used in this study.

an inner diameter of $0.10 \mathrm{~mm}$ except for the case of the paste of $24.3 \mathrm{vol} \%, 0.15 \mathrm{~mm}$. For the pastes of lower particle concentration, 3.9 and $7.4 \mathrm{vol} \%$, it was difficult to control the deposited volume linearly within the air pressure of 20 to $60 \mathrm{kPa}$.

For the paste with the particle content of $13.8 \mathrm{vol} \%$, however, the dispensing was successful and controllable, which is shown as the linear increase of the deposited volume with the air pressure and or dispensing time. During dispensing this paste, the deposited volume of $35 \mathrm{~nL}$ and the deposition time of $1 \mathrm{~s}$, and we could calculate the velocity of the fluid $v=35 \times 10^{-6} \mathrm{~cm}^{3} / \mathrm{s}$, and then the shear rate inside the tube-type nozzle as below,

$$
\dot{\gamma}=\frac{4 Q}{\pi r^{3}}
$$

Then the shear rate is $4 \times 35 \times 10^{-6}\left(\mathrm{~cm}^{3} / \mathrm{s}\right) /\left(\pi \times 0.005^{3}\left(\mathrm{~cm}^{3}\right)\right)=$ $357(1 / \mathrm{s})$. From the data of Fig. 3, the corresponding viscosity for this shear rate was as small as $0.3 \mathrm{~Pa} \cdot \mathrm{s}$, and the shear stress is approximately $100 \mathrm{~Pa}$. Comparing these data with the data in Fig. 5(b), the paste flows in the region of high shear stress over yield stress, and we could say that this stress inside the needle make the fluid start flowing, and all the rheological values are reasonable. We believe that this rheological analysis and discussion would lead us from the know-how to the engineering of dispensing technology.

\subsection{Processing catalyst combustor}

The deposited and dried pastes on the $\mathrm{Si}$ device were fired using a furnace in air atmosphere. The chloride and organic com-

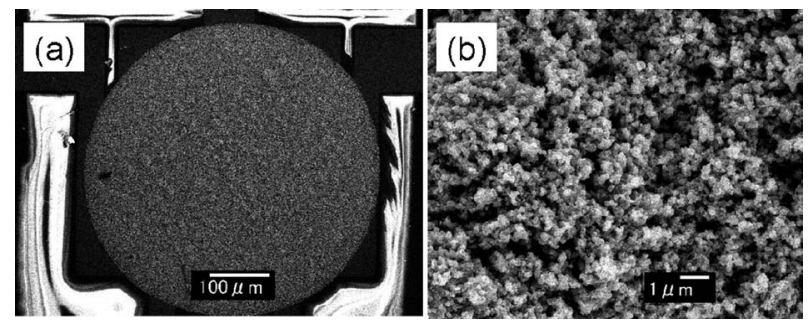

Fig. 10. SEM of sintered catalyst combustor on the membrane of micro-sensor device.

ponent baked out and the color of the paste changed from pink to black. This is due to the precipitation of Pt nanoparticles on the alumina surface, which is reported previously in detail. ${ }^{11)}$ The paste became a circle of thick film after the firing and its typical microstructure is shown in Fig. 10. The thickness of the thick film was ca. $15 \mu \mathrm{m}$ for the paste of TE10 with the particles of $7.4 \mathrm{vol} \%$, and from this dimension, we could roughly estimate the porosity of the film to be ca. $50 \%$. As expected by this porosity value, the microstructure of the catalyst thick film is very porous and functional for the combustion of hydrogen gas. The adhesion of this catalyst film is relatively strong and never peeled off during usual handling or vibration. This adhesion is thought to be favored by the use of fine alumina oxide particles, as discussed elsewhere. ${ }^{12)}$ 

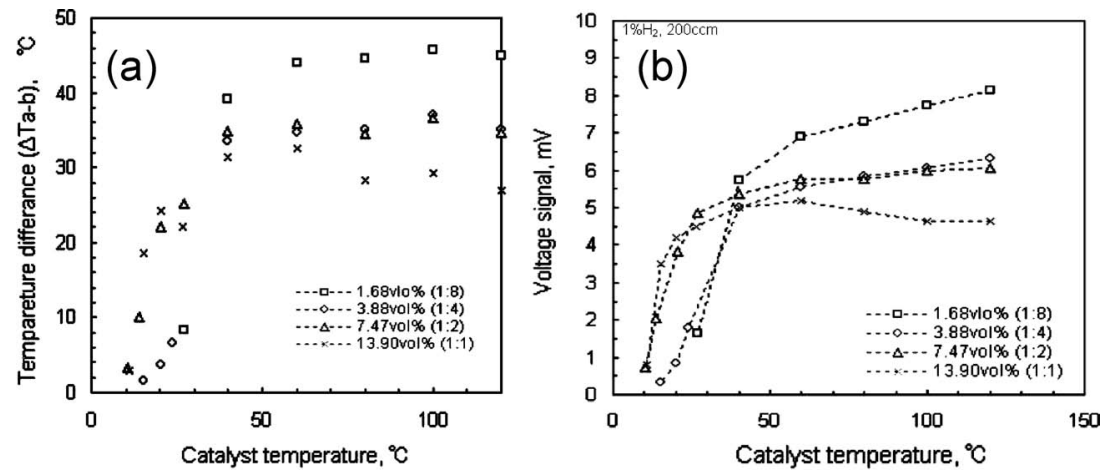

Fig. 11. Combustor performance on the microdevice for various catalyst temperature; (a) temperature difference by combustion, (b) thermoelectric voltage of the micro-device.

\subsection{Performance of the catalyst combustor on micro-device}

Figure 11 shows the hydrogen combustion performance of the catalyst on the microdevices, which is represented by the temperature differential $\Delta T_{\mathrm{A}-\mathrm{B}}\left(\Delta T_{\mathrm{A}-\mathrm{B}}=\Delta T_{\mathrm{A}}-\Delta T_{\mathrm{B}}\right.$, difference of temperature change between the catalyst top surface $A$ and the cold side B), with the corresponding voltage signal, which is developed by thermoelectric or Seebeck effect. ${ }^{6}$ ) It compares the performance of the catalysts of the pastes of different particle concentration, from 1.6 to $13.9 \mathrm{vol} \%$ in the dispersant TE10.

Figure 11 (a) shows relatively higher $\Delta T_{\mathrm{A}-\mathrm{B}}$ of $46^{\circ} \mathrm{C}$ of the device of $1.68 \mathrm{vol} \%$ with catalyst temperature at around $100^{\circ} \mathrm{C}$. This catalyst of lower particle concentration could effectively be heated up by the combustion the thermoelectric device structure because its thickness is relatively thin as several $\mu \mathrm{m}$. As a result, higher thermoelectric voltage signal $\Delta V_{\mathrm{s}} 6-8 \mathrm{mV}$ of the device was obtained compared to others as shown in Fig. 11(b). As the particle concentration in the paste increase, the catalyst on the microdevice becomes thicker and the combustion performance changes. The combustion performance of the catalyst became less temperature dependent as its thickness increase. Furthermore, the thick catalyst also is beneficial for long-term stability as reported recently, ${ }^{13)}$ and the catalyst thickness has been demonstrated to be controllable by changing the particle concentration in the paste.

\section{Conclusions}

Ceramic catalyst pastes for the integration of the combustor patterns onto micro devices have been prepared and their rheological properties have been studied. The catalyst powder of 40 $\mathrm{wt} \%$ Pt-loaded on alumina was mixed with the organic vehicle of terpineol and ethyl cellulose, to make various paste systems. Changing the parameters of the content of particles and the ethyl cellulose in the pastes controlled the viscosity of the paste. While the paste without ethyl-cellulous have shown typical nonlinear behavior for wide shear rate, the paste with $5 \mathrm{wt} \%$ and $10 \mathrm{wt} \%$ ethyl-cellulous have enhanced the fluidic and linear mobility of the paste in the high shear rate.
For the dispensing characteristics of the paste, the dispensing amount and speed of the various paste have been analyzed with parameter of dispensing pressure and the results have been discussed with the rheological behavior of the pastes. The change of the viscosity of the paste induced the thickness of the catalyst on the microdevices and the performance of the catalyst combustor on the microdevices has shown the temperature dependency related to the thickness of the catalyst.

Acknowledgment This work is supported by New Energy and Industrial Technology Development Organization (NEDO), Japan.

\section{References}

1) J. W. Gardner, V. K. Varadan and O. O. Awadelkarim, "Microsensors, MEMS and Smart Devices," Wiley, New York (2001).

2) A. Dieguez, A. Romano-Rodriguez, R. Morante, J. Kappler, N. Barsan and W. Göpel, Sens. Actuators B, 60, 125 (1999).

3) S. Semancik, R. E. Cavicchi, M. C. Wheeler, J. E. Tiffany, G. E. Poirier, R. M. Walton, J. S. Suehle, B. Panchapakesan and D. L. DeVoe, Sens. and Actuators B, 77[1-2], 579-591(2001).

4) A. Cirera, A. Cabot, A. Cornet and J. R. Morante, Sens. Actuators $B, 78[1-3], 151-160$ (2001).

5) J. Cerda, A. Cirera, A. Vila, A. Cornet and J. R. Morante, Thin Solid Films, 391, 265 (2001).

6) W. Shin, K. Tajima, Y. Choi, N. Izu, I. Matsubara and N. Murayama, Sens. Actuators B, 108, 455-460 (2005).

7) J. Lewis, Materials Today, 32-39 (2003).

8) Q. Li and J. Lewis, Adv. Mater., 15, 1639-1643 (2003).

9) W. Shin, M. Nishibori, K. Tajima, L. F. Houlet, Y. Choi, N. Izu, N. Murayama and I. Matsubara, Sens. Actuators, B, 118, 238-291 (2006).

10) J. S. Reed, "Principles of Ceramic Processing 2nd ed., Chapter. Rheology of Saturated System," John Wiley \& Son Inc., New York (1995) pp. 16.

11) Y. Choi, K. Tajima, W. Shin, N. Izu, I. Matsubara and N. Murayama, J. Mater. Sci., 41, 2333-2338 (2006).

12) V. Meille, Applied Catalysis A, 315, 1-17 (2006).

13) M. Nishibori, W. Shin, L. Houlet, K. Tajima, N. Izu, T. Itoh and I. Matsubara, J. Eur. Ceram. Soc., 28, 2183-2190 (2008). 